\title{
Liquor outlet density, deprivation and implications for foetal alcohol syndrome prevention in the Bergriver municipality in the Western Cape, South Africa
}

Yasmin Bowers $^{\mathrm{a}^{* 1}}$, Kirstie Rendall-Mkosi ${ }^{\mathrm{b}}$, Adlai Davids ${ }^{\mathrm{c}}$, Elmarie $\mathrm{Nel}^{\mathrm{d}}$,Nontobeko Jacobs ${ }^{\mathrm{e}}$, and Leslie London ${ }^{\mathrm{e}}$ a Mount Sinai School of Medicine Department of Community and Preventative Medicine International Exchange Program for Minority Students, New York City, NY, USA; $b$ School of Health Systems and Public Health, University of Pretoria, Pretoria, South Africa;

c Human Sciences Research Council, Port Elizabeth, South

Africa;

dMedical Research Council, Pretoria, South Africa; e School of Public Health and Family Medicine, University of Cape Town, Cape Town, South Africa;

Foetal Alcohol Syndrome (FAS) is the most common preventable birth defect in the world, and some South African communities have amongst the highest reported rates. In August 2008, Global Positioning Systems (GPS) and Geographic Information Systems (GIS) were used to collect data on legal and illegal alcohol outlets in the Bergriver municipality. Onehundred and twelve outlets were recorded and towns with the densest distributions (outlet/ $\mathrm{km} 2$ ) were Piketberg and Eendekuil. Spearman coefficients were used to estimate the relationship between alcohol outlet distributions within the study area and the South African Index of Multiple Deprivation (SAIMD). Although not statistically significant, the data are suggestive of an inverse relationship between legal alcohol outlets and deprivation-less deprived areas had higher density of legal alcohol outlets - while the opposite relationship applied for illegal alcohol outlets. GIS provides spatial documentation of determinants of FAS risks amenable to geographically-based prevention strategies, as well as providing baseline data to evaluate the effectiveness of liquor legislation aimed at controlling access to alcohol. Results are being repurposed into health education materials that encourage community action to address the social determinants of health outcomes such as FAS.

Keywords: foetal alcohol syndrome; alcohol accessibility; deprivation; Western Cape; geographic information systems

\footnotetext{
*Corresponding author: Email Yasmin.ct@gmail.com
} 


\section{Introduction}

Foetal Alcohol Spectrum Disorders (FASD), an umbrella term describing the range of symptoms that can be manifested by an individual whose mother drank alcohol during pregnancy, includes the narrower category Foetal Alcohol Syndrome (FAS). FAS is used to describe physical and mental defects including brain damage, facial deformities and growth deficits that an affected child exhibits (Stratton et al, 1996).

Collaborations between the University of Cape Town's School of Public Health and Family Medicine, University of Pretoria School of Health Systems and Public Health, South African Medical Research Council, and the Human Sciences Research Council have contributed to FAS prevention research and outreach within the study area in the Bergriver Municipality, in the Western Cape.

South Africa's Western Cape Province is known to have the highest reported rates of FAS in the world. In the rural area 
of Wellington, 46.4 per 1000 (or 4.64\%) school-entry children aged five to nine years were reported to have FAS, a rate that had risen by about $50 \%$ (to $65.2-89.2$ per 1000 school entry children) in a repeat study in the same area five years later (May et al. 2007 and Viljoen et al. 2005).

Te Water Naude et al. (1998) found a prevalence rate of FAS of $5.7 \%$ amongst children five to eight years old living on farms in the Stellenbosch region. In the Northern Cape Province, Urban et al. (2008) found the prevalence of FAS/partial FAS in grade one children to be $11.9 \%$ (64/536) in De Aar and $7.47 \%$ (97/1299) in Upington. Overall, 67.2 per 1000 children had full FAS features. Maternal risk factors correlated with having a child with FASD compared to non-FASD children in the same community, and relevant to this discussion, were found to be lower education and income levels; higher levels of alcohol intake and weekend bingeing; and having a partner who abuses alcohol (May et al., 2008). A farm-based survey of women of reproductive age done in the West Coast area, including Bergriver Municipality, found that as many as $8.5 \%$ of women were at risk of an alcohol exposed pregnancy which could lead to FASD due to ineffective contraceptive use and high levels of alcohol use (Morojele et al., 2010).

High levels of FAS in South Africa can be traced to a mixture of social, historical and psychological factors. In the Western Cape, part of the problem can be linked to the 
availability of alcohol (London 1999) and the institutional provision of alcohol by colonial settlers to their farm laborers as part of the "dop" (tot) system, which has manifested today in widespread alcohol dependence and misuse (London et al. 1998a; Mcloughlin 2007). The payment of alcohol to farm workers as part of their conditions of employment is no longer legal in South Africa, however, the "dop" system continued into the 1990s (London 1999). 
"Shebeens" are typically unlicenced establishment or even a private house that sells alcohol illegally. The establishments in the study area were often unmarked and often sold unlabeled product. These informal bars are commonly found across South Africa and, in rural areas, may take the form of mobile distributors who travel by car to fixed sales points to sell their products to rural consumers. These outlets have, in the rural Western Cape, effectively replaced the "dop" system, facilitating easy access to alcohol and continue to play a major role in a cycle of poverty and alcohol dependence from which escape is extremely difficult (London 1999).

Research has supported the association between alcohol availability, rates of alcohol consumption, and drinking-related problems (Grover 2000). Investigations in the United States have found strong relationships between alcohol outlet density and adverse outcomes such as alcohol-related hospital admissions, child abuse and neglect, motor vehicle accidents, pedestrian injuries, drunk driving and a range of mortality outcomes (Donnelly et al. 2006).

Outlet density impacts consumption by making low-cost or volume-discounted alcohol available to persons predisposed to drink heavily. High outlet density also reflects heavy drinking norms and preferences, and underlying community features (Gruenewald et al. 1996 and Scriber et al. 2000 cited in 
Weitzman et al. 2003), such as the consequences of the "dop" system.

Studies of natural experiments clarify the relationships between alcohol availability and consumption. These studies indicate that a reduction in alcohol availability caused by worker strikes or prohibitions on sales reduces the rates of alcohol consumption and drinking-related problems (Edwards et al. 1994, cited in Grover 2000).

The issue of outlet density is therefore potentially important in efforts to minimise alcohol-related harm in the community. Research is needed to help determine specific thresholds above which problems in a particular local area will manifest and help understand the relationship between the concentration of specific licence types (or lack thereof) and a range of alcohol-related harms for public benefit (Donnelly et al. 2006).

Our study explores the relationship of alcohol availability and accessibility as it relates to deprivation of an atrisk population susceptible to FAS. Mapping these outlets using GPS and GIS provides data on alcohol accessibility as an indicator of consumption and risk for FAS. Incorporating GIS data, results, and significance into community outreach has proven effective in other parts of Africa. For example, the Map Kibera Project of Kenya started in November 2009 when young Kiberans created the first free and open digital map of their own 
community. Map Kibera is now a complete interactive community information project (Kovačič 2011). A further example is the use of a spatial information system in the management of HIV/AIDS in South Africa, in which an HIV/AIDS database was developed and embedded in a Spatial Information Management System for the Gugulethu Township in Cape Town. The pilot database was used to determine where and when to intervene, improving the quality of care for HIV positive patients, increasing accessibility of service, and delivering a cost-effective mode of information (Busgeeth 2004).

Use of GIS data to contribute to the planning of health promotion interventions and identifying socioeconomic and health rights violations, through the spatial representation of a risk and its relationship to a health outcome, is being increasingly used in public health programmes (Grinzi et al. 2008; Meng et al. 2010). For example, a study in Shiggaon, India used GIS to digitize existing paper maps and created a Public Health Care Information System map and database of the distribution of hospitals, clinics, and dispensaries to enable communities and local agencies to take actions to improve their health (Hanjagi et al. 2007). The authors argued that the visualization of clinical and administrative data in a GIS system allows for data to be used as a spatial decision support tool. 
These projects provide examples of the use of GIS data, created at the local level, to address community health.

In January 2009, there were approximately 900 licensed shebeens, 3200 legal and 30,000 illegal shebeens in the Western Cape (SAPA, 2009). The Western Cape Liquor Act (No. 4 of 2008) was passed in 2008 and one of its key aims was to control the proliferation of drinking places in residential areas, and to crack down on retailers and distributors who supply illegal shebeens through heavy fines, jail terms and forfeiture of assets. Despite protests from shebeen owners, it has been argued that the long-term benefits of the Act for crime prevention and health outweigh the immediate loss of income (Parry 2010).

Determining the density of alcohol outlets (typically per 1000 residents) provides community members, provincial and local officials, and national policymakers with information that can support effective public health intervention strategies. Analyzing liquor licenses in a community at high risk for alcohol-related problems might prevent future issuances that would threaten public health and safety (Grover 2000). GIS data could therefore be used to analyze the impact of Western Cape Liquor Act by providing baseline data against which to compare after changes in enforcement and licensing have been made for legal and illegal alcohol outlets.

In the study area, alcohol outlets have never been mapped and GIS data is limited. The use of GIS mapping data therefore 
provides the opportunity to track alcohol accessibility, as a proxy for risk behaviours, so that appropriate policy decisions such as legislation and programmes such as community-based health promotion interventions can be implemented and evaluated in local communities with the most need. This study therefore aimed to map legal and illegal alcohol outlets in the Bergriver Municipality - a part of the West Coast district in the Western Cape-as part of a larger ongoing FAS prevention study, to provide a baseline measure against which to compare the impact of the introduction of the Western Cape Liquor Act, No. 4 of 2008 and to assess the correlation between liquor outlet density and measures of social deprivation.

The aforementioned literature suggests certain assumptions between alcohol accessibility, density of liquor outlets, alcohol consumption and risk behaviours:

1- There is a strong relationship between alcohol outlets density and drinking related problems

2- Alcohol outlet density makes low cost volume discounted alcohol available to persons predisposed to consume heavily

3- High alcohol outlet density reflects heavy consumption norms and preferences

4- Alcohol outlet density provides data to analyze invention strategies such as licensing policies and public health and safety. 
5- There is an association between alcohol availability, rates of consumption, drinking-related problems

\section{Methods}

The study setting consists of commercial farming areas and surrounding small towns. Some farmworkers live on the farms while others travel to the farms from the small towns daily. Field work was undertaken in August 2008 by two primary researchers (YB and $\mathrm{EN}$ ), who visited the study site to identify and record legal and illegal alcohol outlets. Their field work was assisted by a local community outreach organizer and local police services. Six local towns were visited over a period of three days-Aurora, Eendekuil, Piketberg, Porterville, Redelinghuys, and Velddrift. Due to flooding, Redelinghuys could not be visited. Therefore, liquor outlets in Redelinghuys were plotted on Google Earth using cross-street estimates and exported into ESRI ArcMap.

Using the Garmin Car GPS Device, the latitude and longitude (lat/lon) coordinates were saved as a points of interest along with their attributes such as outlet name, street name and number, legal status, town name and relative size of the outlet. The latter was arbitrarily assigned based on the size of the property from which the outlet operated. The lat/lon file of liquor outlets in the five towns was exported to a spreadsheet format. 
The lat/lon coordinates for liquor outlets located in Redelinghuys were estimated using Google Earth in conjunction with the list of addresses for licensed outlets and local knowledge of the location of known unlicensed outlets. A new shapefile, "FAS Alcohol", contained the locations of all 112 recorded liquor outlets and was created from the lat/lon file using spatial reference data on municipalities and provinces obtained from the GIS Centre of the Human Sciences Research Council (HSRC) (Figures 1 and 2).

Additional spatial data were acquired from the Provincial Government Western Cape Department of Environmental Affairs and Development Planning including: Health Districts (2007), Health Clinics (2002), Landuse (2008), and Street Centreline (2008). The "Clip 2" shapefile of the Department's Landuse data was the smallest area in shapefile format to contain the FAS alcohol outlet study results. The "Join" Feature in ArcMap was used to incorporate the attributes of the "Clip 2" landuse data into "FAS Alcohol", and saved as "FAS Alcohol Landuse." The results were used to create Table 1 on landuse. Chi-squared testing was used to test the association between legality of alcohol outlets and urban versus rural landuse using Microsoft Excel's CHIDIST and 1 degree of freedom. A $p<0.5$ was used as a probability measure for statistical significance.

In this study, alcohol accessibility is defined by alcohol outlets/km2, alcohol outlets/person and alcohol outlets/1000 
persons. These calculations were made using population and density data gathered from the Bergriver Spatial Development Framework: Draft Framework for Discussion (Rodeplan 2007). The percentage and proportion of illegal alcohol outlets were also calculated for each town. Attribute data from "FAS Alcohol" and the alcohol accessibility calculations were used to create Table 2 on legality, population, and alcohol outlet density.

WGS84 was used as the reference coordinate system for all maps. Health data of alcohol-related birth defects and FAS were not available for the study area, nor were data on health outcomes related to pre-natal health (e.g. birthweights) at the scale of this study.

We made use of the South African Index of Multiple Deprivation 2001 (SAIMD 2011) (Noble et al. 2009), which is a composite index reflecting four dimensions of deprivation experienced by people in South Africa: income and material deprivation, employment deprivation, education deprivation, and living environment deprivation (Noble et al. 2009). The SAIMD data was from 2001, the year of the previous national population census. The SAIMD and the component domains of deprivation are presented at datazone level. Datazones are small areas containing approximately the same number of people (average 2000). The datazone level SAIMD therefore provides a fine-grained picture of deprivation in South Africa that enables pockets of deprivation to be identified. For analysis purposes, the 
SAIMD index was used as a marker of deprivation and correlated with liquor outlet density found in this study, i.e. the spatial representation of legal and illegal alcohol outlets.

There are 15 SAIMD datazones within the study, and each datazone was ranked by the number of illegal, legal and total liquor outlets, expressed per 1000 persons, as a measure of alcohol accessibility. The datazones with the greatest number of outlets per 1000 persons received an "OutletRate_Rank" of 1, the next highest received an "OutletRate_Rank" of 2, and so forth.

The same ranking method was done for SAIMD scores as well. The most deprived datazones have lower SAIMD scores - as the scores increase deprivation decreases. Therefore, the datazones with the lowest SAIMD scores received a "SAIMD ranking" of 1 (the most deprived) and the highest SAIMD score of 15 reflected the least deprived zone.

The correlation between alcohol accessibility ranking and the deprivation ranking was estimated using a Spearman Rank Correlation Coefficient ${ }^{2}$. 
Figure 1

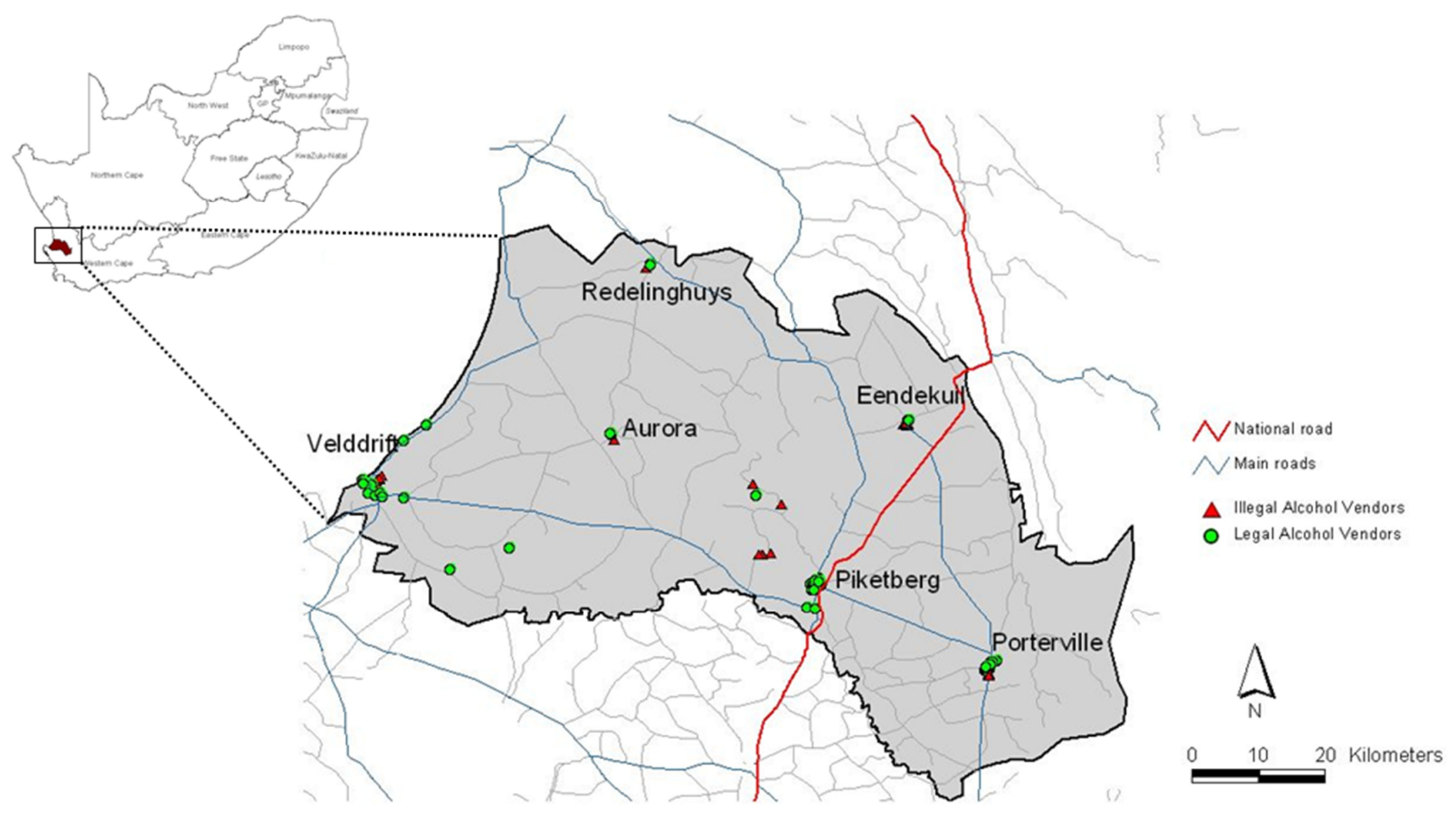




\section{Results}

Figure 1. Legal and illegal alcohol outlets in the study area in the Bergriver Municipality, South Africa

A total of 112 liquor outlets were recorded in the study area (Figure 1), of which 47 (42\%) were illegal outlets. Velddrift, Piketberg and Porterville are the most populated towns within the study area and have a combined $98(88 \%)$ of the recorded 112 liquor outlets.

Eendekuil is a village with a relatively small population of about 1000, and is in a remote location; however, $75 \%$ of its outlets are illegal - the highest percentage in the study.

Table 1. Legal and illegal outlets by landuse and town.

\begin{tabular}{|c|l|r|r|l|l|l|}
\hline Landuse & $\begin{array}{l}\text { Illegal } \\
\text { Alcohol } \\
\text { Outlets }\end{array}$ & $\begin{array}{l}\text { Legal } \\
\text { Alcohol } \\
\text { Outlets }\end{array}$ & Total & $\begin{array}{l}\text { Percent } \\
\text { Illegal } \\
\text { Alcohol } \\
\text { Outlets }\end{array}$ & $\begin{array}{l}\text { Percent } \\
\text { Legal } \\
\text { Alcohol } \\
\text { Outlets }\end{array}$ & $\begin{array}{l}\text { Total } \\
\text { Percentage }\end{array}$ \\
\hline Cultivation & 18 & 24 & 42 & $43 \%$ & $57 \%$ & $37.5 \%$ \\
\hline Aurora & & 1 & 1 & & & \\
\hline Eendekuil & 6 & 2 & 8 & & & \\
\hline Piketberg & 9 & 9 & 18 & & & \\
\hline Porterville & 3 & 8 & 11 & & & \\
\hline Velddrift & & 4 & 4 & & & \\
\hline Mining & & 1 & 1 & $0 \%$ & $100 \%$ & \\
\hline Piketberg & & 1 & 1 & & & $1 \%$ \\
\hline Natural & 3 & 11 & 14 & $21 \%$ & $78.5 \%$ & $12.5 \%$ \\
\hline Piketberg & & 4 & 4 & & & \\
\hline Redelinghuys & & 1 & 1 & & & \\
\hline Velddrift & 3 & 6 & 9 & & & \\
\hline Urban: Residential & & 22 & 46 & $52 \%$ & $48 \%$ & \\
\hline
\end{tabular}




\begin{tabular}{|l|r|r|r|r|r|r|}
\hline Aurora & 1 & 1 & 2 & & & \\
\hline Piketberg & 8 & 8 & 16 & & & \\
\hline Porterville & 3 & 5 & 8 & & & \\
\hline Redelinghuys & 1 & 1 & 2 & & & \\
\hline Velddrift & 11 & 7 & 18 & & & \\
\hline Waterbodies & & 6 & 6 & $0 \%$ & $100 \%$ & $5.3 \%$ \\
\hline Velddrift & 2 & 6 & 6 & & & \\
\hline Wetlands & 2 & 1 & 3 & $67 \%$ & $33 \%$ & $2.7 \%$ \\
\hline Velddrift & 47 & 65 & 112 & $42 \%$ & $58 \%$ & \\
\hline Total & 2 & & & & \\
\hline
\end{tabular}

Illegal outlets (Table 1) tended to be more frequent in urban residential landuse areas compared to other areas (52\% versus $35 \%$; $\mathrm{p}=0.05)$. Nonetheless, it is still noteworthy that in land zoned for cultivation, $42 \%$ of outlets were illegal. 
Table 2. Legality, population and alcohol outlet density.

The highest concentrations of all liquor outlets per km (Table 2) was found in the larger towns (Piketberg, Veldrif and Porterville) but the higest concentrations of all liquor outlets per person was in two of the three small villages (Eendekuil and Aurora).

\begin{tabular}{|c|c|c|c|c|c|c|c|c|c|c|}
\hline \multirow[t]{2}{*}{ Town } & \multirow[t]{2}{*}{ Illegal } & \multirow[t]{2}{*}{ Legal } & \multirow[t]{2}{*}{ Total } & \multirow{2}{*}{$\begin{array}{l}\text { Percent } \\
\text { Illegal }\end{array}$} & \multirow{2}{*}{$\begin{array}{l}\text { Total } \\
\text { Population* }\end{array}$} & \multirow{2}{*}{$\begin{array}{l}\text { Population } \\
\text { Density* }^{*}\end{array}$} & \multirow{2}{*}{$\begin{array}{l}\text { Town Area in } \\
\mathrm{km}^{2} \\
\text { (using } \\
\text { population and } \\
\text { density data*) }\end{array}$} & \multicolumn{3}{|c|}{ Total Alcohol Outlet Density } \\
\hline & & & & & & & & $\begin{array}{l}\text { Outlets/ } \\
\mathrm{km}^{2}\end{array}$ & $\begin{array}{l}\text { Outlet/ } \\
\text { Person }\end{array}$ & $\begin{array}{l}\text { Outlets/ } \\
1000 \\
\text { Persons }\end{array}$ \\
\hline $\begin{array}{l}\text { Aurora } \\
\text { (Aug 5) }\end{array}$ & 1 & 2 & 3 & 33.33 & 420 & $5.9 / \mathrm{km} 2$ & 71.2 & .042 & .007 & 7 \\
\hline $\begin{array}{l}\text { Eendekuil } \\
\text { (Aug 4) }\end{array}$ & 6 & 2 & 8 & 75 & 1000 & $13.5 / \mathrm{km} 2$ & 74.1 & .107 & .008 & 8 \\
\hline $\begin{array}{l}\text { Piketberg } \\
\text { (Aug 4) }\end{array}$ & 17 & 22 & 39 & 43.59 & 11900 & $33.9 / \mathrm{km} 2$ & 351 & .111 & .003 & 3 \\
\hline $\begin{array}{l}\text { Porterville } \\
\text { (Aug 5) }\end{array}$ & 6 & 13 & 19 & 31.58 & 7900 & $28.4 / \mathrm{km} 2$ & 278.2 & .068 & .002 & 2 \\
\hline $\begin{array}{l}\text { Redelinghuys } \\
\text { (Attempted } \\
\text { Aug 5) }\end{array}$ & 1 & 2 & 3 & 33.33 & 840 & $12.4 / \mathrm{km} 2$ & 67.7 & .044 & .0035 & 3.5 \\
\hline
\end{tabular}

* Source: Rodeplan 2007 


\begin{tabular}{|l|l|l|l|l|l|l|l|l|l|l|}
\hline Velddrift & 16 & 24 & 40 & 40 & 10700 & $15.4 / \mathrm{km} 2$ & 694.8 & .057 & .0037 & 3.7 \\
\hline Total & 47 & 65 & 112 & 41.96 & 32760 & $21.3 / \mathrm{km} 2$ & 1537 & .073 & 0.003 & 3.4 \\
\hline
\end{tabular}

Figure 2. Total liquor outlets per 1000 people. (See attached TIFF)

According to the map analysis, Aurora has the highest amount of total alcohol outlets/1000 persons (range 7.4-20.6/1000). Differences between the table and the map of density of outlets/1000 persons are due to difference in the demarcation of the datazone versus the town's actual demarcation. 
Figure 2

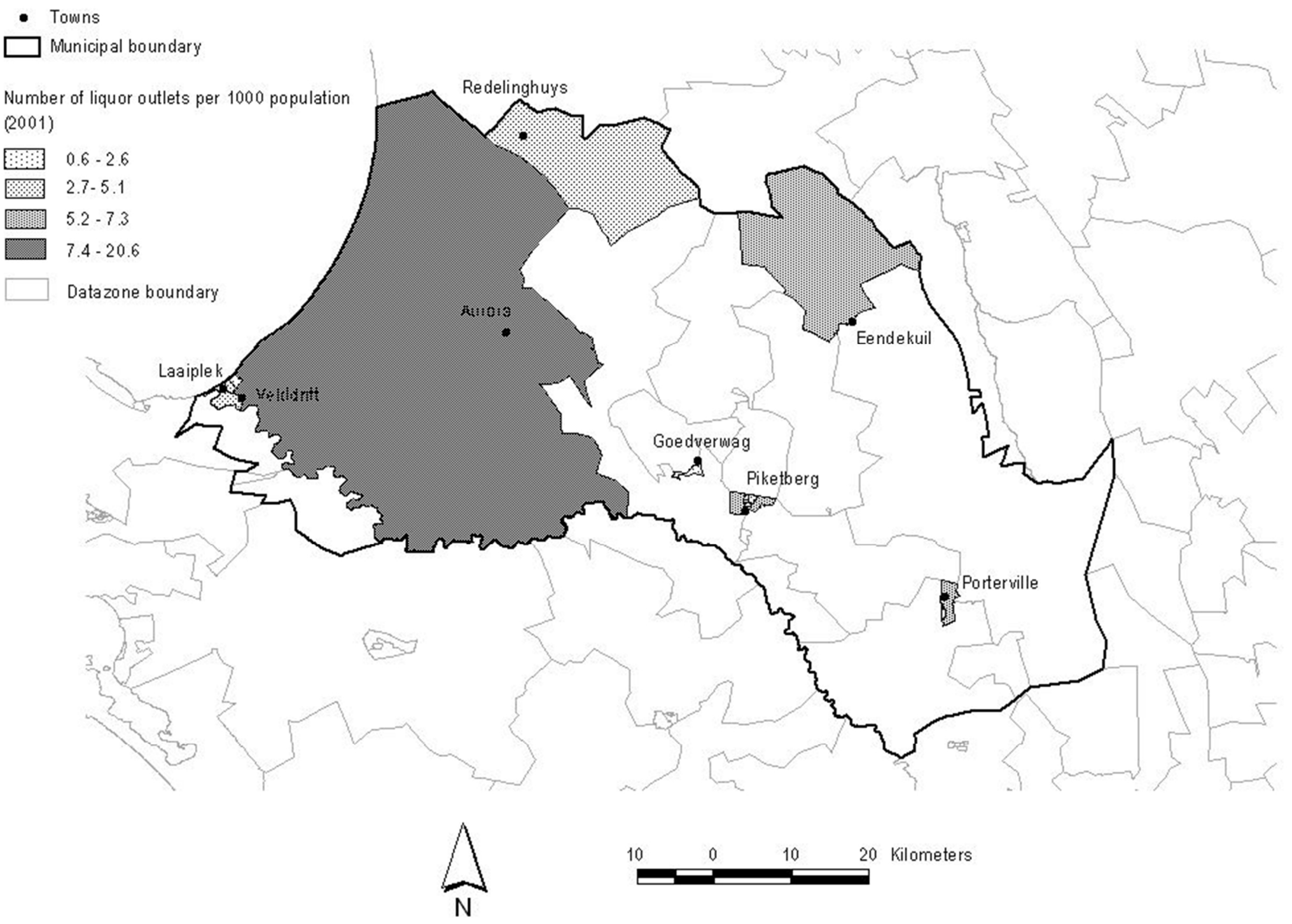


Table 3. Deprivation and alcohol outlet densities.

\begin{tabular}{|c|c|c|c|c|c|c|c|c|c|c|c|c|}
\hline $\begin{array}{l}\text { Data-zone } \\
\text { Area }\end{array}$ & $\begin{array}{c}\text { SAIMD }^{\#} \\
\text { Score }\end{array}$ & $\begin{array}{l}\text { SAIMD }^{\#} \\
\text { ranking }\end{array}$ & $\begin{array}{l}\text { Total } \\
\text { outlets }\end{array}$ & $\begin{array}{l}2001 \\
\text { pop- } \\
\text { ulation }\end{array}$ & $\begin{array}{c}\text { Total } \\
\text { outlet } \\
\text { Density* }\end{array}$ & $\begin{array}{c}\text { Total } \\
\text { outlet } \\
\text { density } \\
\text { rank }\end{array}$ & $\begin{array}{l}\text { Illegal } \\
\text { outlets }\end{array}$ & $\begin{array}{c}\text { Illegal } \\
\text { outlet } \\
\text { density }^{*}\end{array}$ & $\begin{array}{c}\text { Illegal } \\
\text { outlets } \\
\text { density } \\
\text { rank }\end{array}$ & $\begin{array}{c}\text { Legal } \\
\text { outlets }\end{array}$ & $\begin{array}{l}\text { Legal } \\
\text { outlet } \\
\text { density }^{*}\end{array}$ & $\begin{array}{c}\text { Legal } \\
\text { outlet } \\
\text { density } \\
\text { rank }\end{array}$ \\
\hline 103_15 & 18279 & 8 & 7 & 340 & 20.6 & 1 & 1 & 2.94 & 4 & 6 & 17.65 & 1 \\
\hline 103_32 & 21218 & 13 & 13 & 1789 & 7.3 & 2 & 0 & 0.00 & 13 & 13 & 7.27 & 2 \\
\hline 103_66 & 21654 & 15 & 12 & 1705 & 7.0 & 4 & 0 & 0.00 & 13 & 12 & 7.04 & 3 \\
\hline 103_7 & 21476 & 14 & 16 & 1601 & 5.0 & 6 & 0 & 0.00 & 13 & 8 & 5.00 & 4 \\
\hline 103_55 & 15029 & 3 & 3 & 585 & 5.1 & 5 & 1 & 1.71 & 9 & 2 & 3.42 & 5 \\
\hline 103_73 & 15625 & 4 & 6 & 838 & 7.2 & 3 & 4 & 4.77 & 1 & 2 & 2.39 & 6 \\
\hline 103_34 & 18292 & 9 & 6 & 1789 & 3.4 & 9 & 4 & 2.24 & 7 & 2 & 1.12 & 7 \\
\hline 103_37 & 14501 & 1 & 3 & 1789 & 1.7 & 13 & 1 & 0.56 & 10 & 2 & 1.12 & 7 \\
\hline 103_61 & 14758 & 2 & 3 & 2077 & 1.4 & 14 & 1 & 0.48 & 12 & 2 & 0.96 & 9 \\
\hline 103_12 & 18475 & 10 & 11 & 2341 & 4.7 & 7 & 10 & 4.27 & 2 & 1 & 0.43 & 10 \\
\hline 103_39 & 16145 & 5 & 7 & 1789 & 3.9 & 8 & 7 & 3.91 & 3 & 0 & 0.00 & 11 \\
\hline 103_11 & 17110 & 7 & 6 & 2341 & 2.6 & 10 & 6 & 2.56 & 5 & 0 & 0.00 & 11 \\
\hline
\end{tabular}




\begin{tabular}{|l|c|c|c|c|c|c|c|c|c|c|c|c|}
\hline 103_59 & 16273 & 6 & 5 & 2077 & 2.4 & 11 & 5 & 2.41 & 6 & 0 & 0.00 & 11 \\
\hline $103 \_23$ & 18765 & 12 & 3 & 1407 & 2.1 & 12 & 3 & 2.13 & 8 & 0 & 0.00 & 11 \\
\hline $103 \_38$ & 18507 & 11 & 1 & 1789 & 0.6 & 15 & 1 & 0.56 & 10 & 0 & 0.00 & 11 \\
\hline
\end{tabular}

* Density expressed as outlets/1000 persons

\# South African Index of Multiple Deprivation (Noble et al. 2009)

Figure 3. Deprivation ranking for the study area. (See attached TIFF)

Redelinghuys and Eendekuil are located in more deprived datazones, while Velddrift and Aurora are located in datazones that are moderately deprived. 
Figure 3

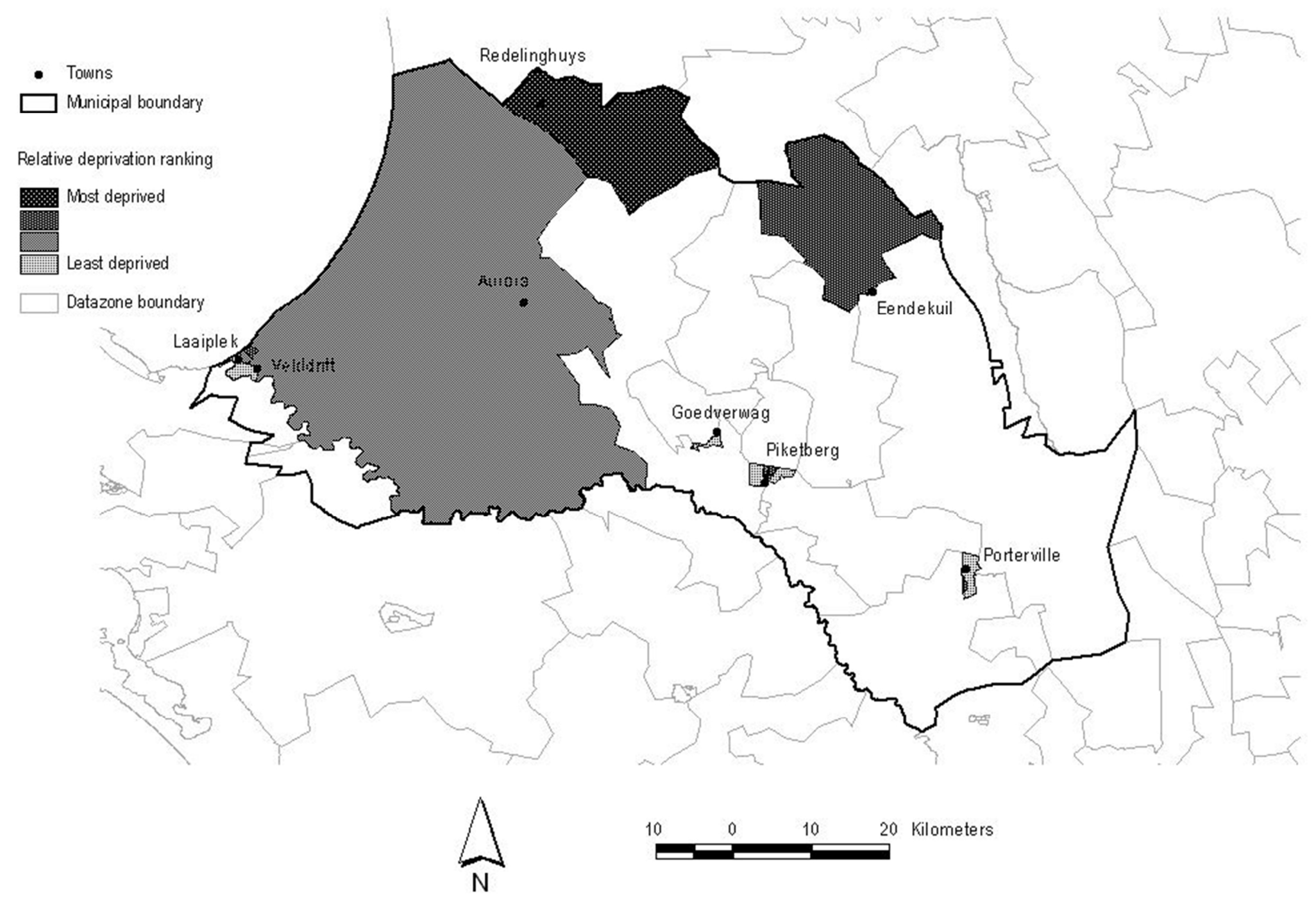


The lowest SAIMD deprivation score (14501) represented the most deprived area of the study, which is DZ 103_37. Zones DZ 103_15 and DZ 103_32 received an Outlets Density_Rank of 1 and 2, and corresponding deprivation ranks of 8 and 13, meaning that these two zones have the most alcohol outlets, yet are modestly or not deprived at all. However, it must be noted that these zones mostly have legal alcohol outlets-one illegal and six legal for DZ 103_15 and zero illegal and 13 legal for DZ 103_32. Here, lack of deprivation is associated with legal alcohol accessibility, and since legal alcohol outlets have regulated trading hours, this in turn could actually mitigate accessibility (i.e. restrict availability within operating hours).

Based on 15 observation points, the Spearman's Rank Correlation between alcohol outlet and SAIMD deprivation was $0.38(\mathrm{p}=0.14)$ for illegal outlets and $-0.20(\mathrm{p}=0.46)$ for legal outlets.

\section{Discussion}

Density of alcohol outlets is an indicator of alcohol accessibility and an indicator of consumption. Although, various studies have demonstrated a relationship between alcohol outlet density, accessibility and consumption, this study could not test the assumptions. This limitation highlights the need for future research on factors that define and impact density, access, and availability, in addition to testing and quantifying the relationships between them. 
There is a difference between density measured by area and measured per population within the study site. Aurora and Eendekuil have the highest outlets/1000 persons, but Piketberg and Eendekuil have the highest outlets $/ \mathrm{km}^{2}$. All three towns should be prioritized for FAS prevention and different measures of accessibility and their significance should be further explored in the future.

Landuse affects the location of alcohol outlets (e.g. the location of legal outlets is shaped by zoning laws and illegal shebeens are located where there is a stable residential customer base). In this study, illegal shebeens were more common in urban than non-urban areas. Although this association was only marginally significant $(\mathrm{p}=0.05)$, sample size may have been too small to enable adequate power for this comparison. Nonetheless, "Cultivation" and "Urban Residential" landuse categories have the most alcohol outlets, which helps to focus the scope of FAS prevention initiatives.

Illegal liquor outlets constituted $42 \%$ of all liquor outlets. It is possible that this is an undercount, given the suggestion that illegal outlets comprise over $90 \%$ of all liquor outlets in the province (SAPA 2009). In South Africa, illegal liquor outlets are generally located within poor, dense settlements called "townships". In this study, there was also a concentration in rural town areas, although the density in land zoned for farming was as high as for the total sample $-42 \%$ of outlets in farming areas 
were illegal, and FAS is particularly common in farm worker communities (te Water Naude, 1998; Viljoen et al, 2005; May et al, 2007; May et al, 2008). According to police escorts, alcohol sales and distribution are difficult to track, monitor, and regulate. Sometimes an illegal outlet can be shut down and a replacement can often pop-up the next day and even next door. Neighbours also work together by warning one another of police activity. Farmers anecdotally complain about illegal outlets operating from mobile stations in the farming areas of the Western Cape with alcohol literally sold from the back of a vehicle by an itinerant entrepreneur.

Piketberg's population of 11,900 was reported as having 17 illegal shebeens, or 1.4 per 1000, compared to De Aar's population of 30,000 having more than 100 illegal shebeens, which is roughly 3.3 per 1000 (Bateman 2010). For perspective, in 2000, FAS incidence in De Aar was $12 \%$ in grade one students (Urban et al. 2008). The association between FAS incidence and illegal shebeens should be further explored and could aid in predicting FAS incidence in Piketberg and other towns where no such incidence data exist.

There are no health facilities in Redelinghuys (population 840) or Eendekuil (population 1000), so accessing health care for residents involves travel to larger towns. Eendekuil has a relatively high proportion of illegal alcohol outlets in that six of the total eight are illegal. This high 
proportion of illegal alcohol outlets coupled with its isolation from health facilities could increase vulnerability to alcoholrelated harm. The lack of health resources is exacerbated by alcohol accessibility and raises concerns about the health rights (e.g. accessibility, availability, acceptability and quality of services) of marginalized rural communities.

During data collection, a culture of tolerance of alcohol availability was exemplified by police escorts who could identify illegal shebeens but did nothing about inebriated people lying in the streets. Changing this culture is best effected by comprehensive interventions that include actions to reduce the upstream determinant of alcohol abuse.

Due to the sensitive nature of the study results, a map of easily identifiable legal and illegal alcohol outlets could have unintended consequences where users may use the map to find and purchase alcohol. Instead, displaying overall outlet densities, especially in known FAS outreach areas could act as a powerful educational tool to change behaviours in the community. The map would display smaller regions where FAS is prevalent, and each polygon would have a corresponding color of intensity based on the legal and illegal outlet densities. Therefore, the map would display densities as polygons and not individualize points. The resulting tool will serve as information for community level lobbying against an increase in the density of liquor outlets, whether legal or illegal. This work is currently ongoing in the 
study area in collaboration with local community partners, alongside other preventive actions.

Although not statistically significant the correlations found in this study suggest differing associations between socioeconomic status (SES) and whether liquor outlets were legal or illegal. A modestly positive association was found between deprivation and illegal outlet density (0.38), but an inverse association was found for the relationship between deprivation and legal outlet density (-0.20). This suggests that, at the time of the study, the existing regulatory environment had encouraged illegal outlets in more deprived areas, whereas legal outlets were clustered in less deprived areas. This might be explained by less deprived areas having slightly higher aggregate levels of disposable income to support legal outlets, greater entrepreneurship amongst those less desperately poor and different levels of social cohesion. Evidence from the literature suggests that social cohesion has a complex relationship with general health outcomes (Wilkinson 1997) and with alcoholrelated health outcomes (Braithwaite et al. 2009), a relationship that warrants further exploration in other studies.

There are two important inferences if the suggestive finding of a differential effect by legality of outlet on the association of SES with outlet density in this study is valid. Firstly, it implies that the impact of alcohol availability in poorer communities might be overlooked if the focus of interventions is 
only on licensed outlets. Secondly, the finding also supports the intent of the Western Cape Liquor Act, which is to bring illegal outlets into a system of regulation - to count them in, rather than ignore them, so as to minimise harms from unregulated distribution of alcohol. Current impediments to regulating alcohol outlets in deprived areas are caused by their unstable nature and the fact that they are inconspicuous and easy to open and close. Therefore, it is important that such interventions, especially in poorer deprived areas, must not overlook illegal outlets.

\section{Conclusion}

The GPS collection of legal and illegal alcohol outlets provided GIS data to enhance the existing FAS prevention advocacy in the Bergriver Municipality of the Western Cape. The study has documented evidence of alcohol accessibility which is an indicator of a behavioural risk that does predispose to FAS. Future data collection is needed to analyze the impact of the Western Cape Liquor Act, No. 42008 on the frequency and distribution of legal and illegal alcohol outlets in the study area. For example, given the intent of the Act to regularise and regulate small and medium alcohol outlets, it would be expected that the relative distribution of legal to illegal outlets would change, as would their locations. 
The formal documentation of alcohol outlets also allows for the future investigation of health implications, such as FASD and alcohol-related trauma or death. However, it will be important to collect health data at the same scale as alcohol outlet density for further spatial analysis of the impact of alcohol accessibility on health. In this way, GIS documentation can offer a visual action strategy for FAS monitoring, intervention, and regulation. 


\section{Acknowledgements}

This publication was supported by the 'Centers for Disease Control and Prevention (CDC)' [Cooperative Agreement Number 1 U01 DD00044] Its contents are solely the responsibility of the authors and do not necessarily represent the official views of the CDC. Additional acknowledgment include: Fogarty International Centre;Mount Sinai School of Medicine International Exchange Program for Minority Students; Di-anne Oktober is acknowledged for her field work assistance in Piketberg; Police escorts; and Human Sciences Research Council.

\section{Notes}

1. GIS Data Source: Human Sciences Research Council http://www.hsrc.ac.za/

2. Online calculator at: http://www.wessa.net/rankcorr.wasp

\section{Word Count}

4510

This paper has not been and will not be submitted concurrently for publication elsewhere.

\section{References}


Bateman, C., 2010. FASD -- De Aar mums get beyond the 'tippling point'. South African Medical Journal, 100 (11), 706-708.

Bergriver Spatial Development Framework: Draft Framework for Discussion, 2007. Bellville: Rode Plan Spatial and Development Planners and Economists-A Division of Rode and Associates. Available from: www.rodeplan.co.za [Accessed 12 Aug 2008].

Braithwaite, R.L., Taylor, S.E., and Treadwell, H.M., eds., 2009. Health Issues in the Black Community 3rd edition. San Francisco, CA: Jossey-Bass.

Busgeeth, K. and Rivett, U., 2004. The use of a spatial information system in the management of HIV/AIDS in South Africa. International Journal of Health Geographics [online], 3 (13). Available from http://www.ijhealthgeographics.com/content/pdf/1476-072X-3-13.pdf [Accessed 24 January 2012].

Donnelly, N., Poynton, S., Weatherburn, D., Bamford, E., and Nottage, J., 2006. Liquor outlet concentrations and alcohol-related neighbourhood problems. Alcohol Studies Bulletin. Sidney: NSW Bureau of Crime and the Alcohol Education and Rehabilitation Foundation Statistics and Research, (8), 1-16.

Grinzi, P., Bazemore, A., and Phillips Jr., R.L., 2008. Navigating general practice The use of geographic information systems. Australian Family Physician, 37 (10) $855-858$.

Grover, P., ed., 2000. Preventing problems related to alcohol availability: Environmental approaches. Reference Guide: Third in the Prevention Enhancement Protocols System (PEPS) Series [online]. Available from: http://socrates.berkeley.edu/ pbd/pdfs/pepsmanual.pdf [Accessed 18 September 2008].

Hanjagi, A., Srihari, P., and Rayamane, A.S. 2007. A Public Health Care Information System Using GIS and GPS: A Case Study of Shiggaon. In: P.C. Lai and A.S.H Mark, eds. GIS for Health and the Environment. New York, NY: Springer Berlin Heidelberg, 243-255.

Kovačič, P. Making the invisible visible: Creating Community-Driven Data for Informal Settlements. Available from: http://www.africageospatialforum.org/2011/Proceeding/Primo\%C5\%BE\%20Kovacic. pdf [Accessed 24 January 2012].

London L., 1999. The "dop" system, alcohol abuse and social control amongst farm workers in South Africa: a public health challenge. Social Science \& Medicine, 48 (10), 1407-1414.

London L., Nell V., Thompson M.L., and Myers J.E., 1998. Health status among farm workers in the Western Cape - collateral evidence from a study of occupational hazards. South African Medical Journal, 88 (9), 1096-1101.

London L., Sanders D., and te Water Naude J., 1998. Farm workers in South Africa the challenge of eradicating alcohol abuse and the legacy of the "dop" system. South African Medical Journal, 88 (9), 1092-1095.

May, P.A., Gossage, J. P., Marais, A.-S., Adnams, C. M., Hoyme, H. E., and Jones, K. 
L., 2007. The epidemiology of fetal alcohol syndrome and partial FAS in a South African community. Drug and Alcohol Dependence, 88 (2-3), 259-271.

May, P. A., Gossage, J. P., Marais, A.S., Hendricks, L. S., Snell, C. L., and Tabachnick, B.G., 2008. Maternal risk factors for fetal alcohol syndrome and partial fetal alcohol syndrome in South Africa: a third study. Alcoholism: Clinical and Experimental Research, 32 (5), 738-753.

McLoughlin J. P., 2007. Consumption and problem drinking amongst farm workers in the rural Western Cape: prevalence and risk factors. Thesis (MPH). University of Cape Town.

Meng, G., Law, J. and Thompson, M.E., 2010. Small-scale health-related indicator acquisition using secondary data spatial interpolation. International Journal of Health Geographics [online], 9 (50). Available from: http://www.ijhealthgeographics.com/content/9/1/50 [Accessed 26 Jan 2012].

Morojele, N.K., London, L., Olorunju, S.A., Matjila, M.J., Davids, A.S., and Rendall-Mkosi, K., 2010. Predictors of risk of alcohol-exposed pregnancies among women in an urban and a rural area of South Africa. Social Science and Medicine, 70 (4), 534-542.

Noble, M., Barnes, H., Wright, G., McLennan, D., Avenell, D., Whitowrth, A., and Roberts, B., 2009. The South African Index of Multiple Deprivation 2001 at the Database Level [online]. Pretoria: Social Development Department, Republic of South Africa Available from: http://www.casasp.ox.ac.uk/docs/SAIMD\%20report\%2022\%20June\%202009.pdf [Accessed 17 February 2012].

Parry C., 2010. Alcohol policy in South Africa: a review of policy development processes between 1994 and 2009. Addiction, 105(8), 1340-5.

SAPA, 2009. Shebeen owners protest W Cape liquor Act. Mail and Guardian Online. Cape Town: South African Press Association. Available from: http://www.mg.co.za/article/2009-01-27-shebeen-owners-protest-w-cape-liquor-act [Accessed 16 October 2010].

Stratton, K.R., Howe, C.J., and Battaglia, F.C., eds., 1996. Fetal alcohol syndrome diagnosis, epidemiology, prevention, and treatment. Committee to Study Fetal Alcohol Syndrome Division of Biobehavioral Sciences and Mental Disorders Institute of Medicine. Washington, DC: National Academy Press.

Te Water Naude, J., London L., Pitt B., and Mohamed C., 1998. The DOP system around Stellenbosch - results of a farm survey. South African Medical Journal, 88 (9), 11021105 .

Viljoen, D., Gossage, J.P., Brooke, L., Adnams, C.M., Jones, K.L., Robinson, L.K., Hoyme, H.E., Snell, C., Khaole, N.C.O., Kodituwakku, P., Asante, K.O., Findlay, R., Quinton, B., Marais, A., Kalberg, W.O., and May, P.A., 2005. Fetal Alcohol Syndrome epidemiology in a South African community: a second study of a very high prevalence area. Journal of Studies on Alcohol, 66 (5), 593-604.

Urban, M., Chersich, M.F., Fourie, L.A., Chetty, C., and Olivier, L., 2008. Viljoen D. Foetal alcohol syndrome among grade one schoolchildren in Northern Cape Province: prevalence and risk factors. South African Medical Journal, 98 (11), 877-882. 
Weitzman, E.R., Folkman, A., Folkman, K.L., and Wechsler, H., 2003. The relationship of alcohol outlet density to heavy and frequent drinking and drinkingrelated problems among college students at eight universities. Health \& Place 9 (1), $1-6$.

Wilkinson, R., 1997. Comment: Income, Inequality, and Social Cohesion. American Journal of Public Health, 87 (9), 1504-1506. 